\title{
O desafio da ambientalização na formação universitária
}

\author{
The challenge of the university training environmentalization
}

\author{
Vania Silva de Souza Bilert' \\ ' Mestre em Desenvolvimento Regional, Professora do Departamento de Secretariado Executivo, \\ Universidade Estadual do Centro-Oeste - UNICENTRO, Guarapuava, PR, Brasil
}

\section{Resumo}

Durante muito tempo as questões ambientais foram tratadas de forma isolada, com relação aos fatores sociais, econômicos, culturais, entre outros. Todavia, nas últimas décadas, a preocupação com a problemática ambiental passou a se inserir nos territórios curriculares de diversas instituições de ensino, com destaque a universidade. Neste sentido, o objetivo deste estudo é analisar como ocorre a incorporação da temática ambiental no processo de formação universitária, nas esferas do ensino, pesquisa e extensão. O estudo caracteriza-se como um estudo de caso de abordagem qualitativa e a coleta dos dados foi realizada por meio de entrevistas. Como lócus de pesquisa, selecionou-se uma universidade pública estadual do Paraná. Os resultados indicaram que a discussão ambiental na universidade ainda é um processo novo, repleto de desafios e anseios dos sujeitos envolvidos, mas que está iniciando as demandas para uma formação socioambiental.

Palavras-chave: Ambiental; Universidade; Problemática.

\begin{abstract}
For a long time the environmental issues were addressed in isolation, with respect to social, economic, cultural factors, among others. However, in recent decades the concern with environmental issues began to insert themselves into curricular areas of several educational institutions, notably the University. In this sense, the objective of this study is to analyze how the incorporation of environmental issues in the process of university education in the spheres of education, research and extension occurs. The study is characterized as a case study with a qualitative approach, and data collection was conducted through interviews. As a locus of research, we selected a state public university of Paraná. The results indicated that the environmental discussion in the university is still a new process, filled with challenges and desires of the individuals involved, but that is initiating the demands for environmental training.
\end{abstract}

Keywords: Environmental; University; Problematic. 


\section{INTRODUÇÃO}

Nos últimos anos, a sociedade passou por grandes transformações, foram muitos os avanços conquistados pela sociedade no campo tecnológico, científico, cultural, econômico, social e político. Isso, no entanto, demandou uma série de adequações e reconfigurações do meio ambiente, o que é evidenciado pela problemática socioambiental nos dias de hoje (SACHS, 2002).

No entanto, as transformações e avanços preconizados acarretaram graves problemas sociais e ambientais. Assim, a universidade é colocada perante o desafio de discutir as consequências dos efeitos do desenvolvimento sobre o meio ambiente, não apenas como viabilização de meios para proteção dos recursos naturais, mas a partir da compreensão das inter-relações entre os aspectos econômicos, sociais, culturais e éticos, em uma abordagem contextualizada pela integração dos saberes.

Sob o ponto de vista de Leme et al.(2012, p 7), "as universidades têm sido e continuarão sendo motor de progresso e bem-estar, não se pode ignorar que muitos dos problemas ambientais têm origem justamente nas decisões tomadas por políticos, administradores e técnicos que passaram por suas salas de aula". Daí a necessidade de inserir a temática ambiental na formação universitária.

Tonso (2012), por sua vez, argumenta que a integração da discussão ambiental na universidade pode ser denominada de "ambientalização universitária". E destaca que ambientalizar a universidade não é somente introduzir a temática ambiental no currículo através de atividades de ensino, pesquisa ou extensão, ou mesmo na gestão universitária. O que se concebe com a ideia de ambientalização é o reconhecimento de uma formação universitária que incorpore as questões socioambientais no processo de formação.

A discussão ancora-se na necessidade de se perceber, atualmente, a responsabilidade da universidade na formação de profissionais aptos a abordar os problemas, considerando a complexidade de suas dimensões. Logo, a universidade deve assumir o papel de agente de mudança da realidade ambiental, contribuindo com alternativas para a superação dos diversos problemas ambientais. Para isso, e cada vez mais, torna-se necessária uma articulação das questões ambientais ao ensino, à pesquisa e à extensão.

Nesta perspectiva, este estudo tem como objetivo analisar como ocorre a incorporação da temática ambiental no processo de formação universitária, nas esferas do ensino, pesquisa e extensão.

O estudo justifica-se pela necessidade de compreensão da complexidade ambiental, principalmente a partir da articulação do problema ambiental com o contexto social, cultural, histórico, político, ideológico e econômico; e, desta forma, a universidade constitui um espaço que deve internalizar, cada vez mais, os desafios e os problemas do mundo atual, e, principalmente, desenvolver uma maior consciência da população no que tange às questões ambientais.

\section{METODOLOGIA}

Esta pesquisa adotou a abordagem qualitativa que, segundo Richardson (1999), visa a compreensão de significados e características situacionais.

A pesquisa caracteriza-se como um estudo de caso. A opção pelo estudo de caso deve-se, sobretudo, à inquietação quanto a responder questões de "como", ou seja, identificar "como" a temática ambiental vem sendo incorporada nas discussões universitárias.

Sob esta ótica, Yin (2005) ressalta que a estratégia de estudo de caso pode ser conduzida pelo desejo de realizar generalizações amplas que as evidências de estudo de caso podem trazer. $\mathrm{O}$ autor, ainda, observa que o estudo de caso é uma metodologia preferida ao investigar eventos contemporâneos, em situações quando o investigador não possui controle ou possui pouco controle sobre os eventos. A investigação de eventos contemporâneos propicia suscitar discussões desconhecidas ou, até mesmo, não entendidas em um contexto mais amplo, no que tange aos envolvidos no processo.

A população deste estudo é composta por cinco chefes de departamento e quatro professores. Os cursos selecionados para a pesquisa foram os cursos de graduação em Administração, Ciências Contábeis, Ciências Econômicas, Serviço Social e Secretariado Executivo, sendo que estes cursos estão lotados no Centro de Ciências Sociais Aplicadas de uma universidade pública estadual, situada no município de Guarapuava, estado do Paraná. 
Para melhor identificação dos sujeitos na análise dos dados, foram atribuídos códigos, assim identificados:

CD1 - Chefe de departamento do curso de Serviço Social;

CD2 - Chefe de departamento do curso de Ciências Contábeis;

CD3 - Chefe de departamento do curso de Administração;

CD4 - Chefe de departamento do curso de Secretariado Executivo;

CD5 - Chefe de departamento do curso de Ciências Econômicas.

Com relação aos professores, participaram da entrevista professores ministradores de disciplinas obrigatórias que abordam questões ambientais, sendo assim classificados:

P1 - Professor do curso de Ciências Econômicas, disciplina: Economia ambiental;

P2 - Professor do curso de Secretariado Executivo, disciplina: Fundamentos de responsabilidade social e profissional em secretariado Executivo;

P3 - Professor do curso de Serviço Social, disciplina: Serviço Social e Sustentabilidade;

P4 - Professor do curso de Administração, disciplina: Gestão Socioambiental.

Convém destacar que, devido a não identificação de disciplinas obrigatórias que abordassem as questões ambientais no curso de Ciências Contábeis, este curso não teve nenhum professor participante da entrevista.

O instrumento de coleta de dados, utilizado para o desenvolvimento desta pesquisa, foi a entrevista estruturada que, segundo Hair Jr. et al. (2005), é uma técnica em que o entrevistador utiliza a mesma sequência de perguntas predeterminadas para cada entrevista. Desta forma, ela é conduzida do mesmo modo e cada entrevistado tem a mesma oportunidade de responder as perguntas.

Após a realização das entrevistas, o primeiro passo da análise foi a transcrição das entrevistas gravadas. A transcrição foi feita pela própria pesquisadora, já que, conforme Jovchelovitch e Bauer (2002), é recomendado que os próprios pesquisadores façam as transcrições.

Com relação a análise dos dados, utilizou-se a análise de conteúdo que, conforme Bardin (1994), é uma técnica de análise de comunicações que busca a descrição objetiva do conteúdo manifesto da comunicação e, ainda, permite inferências sobre as mensagens. A análise do conteúdo permite o recorte das mensagens de acordo com expressões e temas que tenham interação com os objetivos da pesquisa e percepção do pesquisador, seja nas expressões, contradições e, até, nas repetições das mensagens. Desta forma, a realização da análise e sistematização das falas dos entrevistados converge para a produção da versão escrita do texto.

Nesta perspectiva de análise dos dados, destaca-se que, neste estudo, foi utilizada a triangulação, com ênfase na triangulação dos dados coletados com a teoria, conforme sugerido por Yin (2005), tendo em vista a corroboração dos fatos ou fenômenos.

A triangulação tem recebido grande atenção das Ciências Sociais nos últimos anos, pois se utiliza de dados da pesquisa empírica com a complementação - neste caso, a teoria - com o objetivo de auxiliar na discussão dos resultados. Assim, ela possibilita diversos contextos de interpretação e o surgimento de novos questionamentos (YIN, 2005).

\section{RESULTADOS E DISCUSSÃO}

Nesta seção, apresentam-se os resultados e a análise do estudo realizado com os chefes de departamento e professores.

Os resultados das entrevistas mostram que a universidade ainda não é um território aberto ao diálogo da problemática ambiental e que o grande problema é que as áreas ainda são territórios fechados, onde prevalece o aspecto técnico e até econômico das áreas. Assim, os espaços de discussão tornam-se espaços de embates, conforme destacado pelo CD4 no excerto a seguir.

[...] quando são cursos específicos, a universidade incentiva muito fortemente, mas quando se trata de cursos afins, cursos de negócios, nós temos uma barreira, uma resistência muito grande por parte da própria universidade para financiar estes projetos da área ambiental. Nós temos a liberdade de propor, mas dificilmente ela vai passar com incentivo financeiro da universidade, ou até mesmo da Fundação Araucária, do CNPQ, porque a universidade ainda entende como 
um todo que os cursos que têm que cuidar disso são engenharia ambiental, engenharia florestal e talvez o curso de geografia [...] aqui na universidade isso ainda é muito sedimentado. Cada curso na sua especialização. As pessoas ainda não aprenderam a trabalhar com esse enfoque interdisciplinar de projetos [...] (CD4)

Nesta perspectiva, uma importante observação sobre os espaços da temática ambiental no campo educacional é feita por Farias (2008), que aponta que os pesquisadores identificados com a temática ambiental, ou mesmo os denominados educadores ambientais, atuam em um cenário permeado por lutas, que consistem, principalmente, na busca por espaços para afirmar a existência de um campo e buscar articulações, tanto políticas como acadêmicas, que fortaleçam, propiciem visibilidade e, por conseguinte, consolidem a produção política e cultural do campo socioambiental.

A partir do argumento do entrevistado CD4, foi observado que a dificuldade vai além da universidade, ou seja, que a resistência também esbarra nos órgãos que financiam projetos, citados no excerto como Fundação Araucária e CNPQ - Conselho Nacional de Desenvolvimento Científico e Tecnológico.

Com relação à existência de documentos institucionais, leis e regulamentos estaduais e/ou nacionais que norteiam a prática da educação ambiental, observou-se que apenas dois entrevistados demonstraram conhecimento sobre a política nacional de educação ambiental. Seguem dois fragmentos selecionados:

Inclusive a inserção da discussão socioambiental, é, em nível maior, uma exigência do ministério da educação. Então a partir daí que foi se adotando, e uma exigência legal, porque você precisa abordar esses temas, não podemos ficar alheios, só trabalhar a parte técnica, só trabalhar a parte prática/pragmática, sem abordar as questões culturais, sociais, que estão sendo temas hoje de discussão em nível mundial, é uma obrigatoriedade. Existe uma parte legal que vem exigir que seja trabalhada, e é algo que vem realmente contribuir para um desenvolvimento social, cultural melhor de nossos acadêmicos (CD3)

Tem uma legislação do MEC, um decreto, que impõe essa questão ou transversalmente a questão ambiental ou em forma de disciplina, ou a inclusão em alguma disciplina esse conteúdo. No caso da nossa universidade, ela tem a disciplina. É uma legislação que está exigindo isso dentro dos cursos (P3).

Neste ínterim, destaca-se que um entrevistado levantou a hipótese de que as discussões ambientais possam estar inseridas em documentos como o PDI - Plano de Desenvolvimento Institucional:

[...] aqui na universidade eu nunca ouvi falar, e olha que eu transito em todas as esferas [...] nunca ouvi falar que essas discussões tenham sido pautas da universidade. Pode ser que estejam inseridas nos documentos como por exemplo o PDI [...] (CD4)

Vale frisar uma identificação importante da pesquisa, isto é, que a abordagem disciplinar da educação ambiental na universidade existe não devido a diretrizes institucionais, nem governamentais, mas por consciência do próprio corpo docente quanto à construção da matriz curricular do curso. Isso foi concluído pela fala de dois entrevistados.

[...] veio da gente perceber, ver que esta era uma demanda da realidade [...] é o que a gente sempre diz: fazer uma análise de conjuntura, olhar as relações do momento, os problemas que aparecem $[\ldots](\mathrm{CD} 1)$

Por tendência de currículo mesmo. Hoje, se você não tiver algo voltado para a sustentabilidade, gestão socioambiental, você acaba pecando internamente nas organizações [...] (CD3)

A ausência de conhecimento sobre leis, documentos, entre outros mecanismos que norteiam a educação ambiental, é um fator comum, principalmente junto ao público docente. Apesar da polêmica que é gerada em eventos, fóruns e espaços de discussão da temática ambiental, e em alguns casos 
quando integram documentos oficiais e propostas curriculares institucionais, a discussão ainda fica muito restrita a grupos de estudo da temática (FARIAS, 2008).

A partir da discussão precedente, observa-se que a inserção da temática ambiental nos cursos é de responsabilidade de cada departamento, independente da influência do setor ou de regulamentações no âmbito institucional da universidade. Com efeito, o que se constata nas análises das entrevistas é que, embora existam pesquisas sobre a temática ambiental na universidade, a discussão ainda não tem avançado muito. Em alguns casos, ainda está atrelada a uma visão tendenciosa relacionada aos fatores mercadológicos, o que se comprova no argumento do entrevistado CD3 ao afirmar que a universidade "[...] tem que se inserir no contexto, porque você não pode ficar alheio ao que está ocorrendo em todas as demais instituições".

Além disso, o argumento do entrevistado CD4 ainda explicita que a universidade não está incentivando as atividades de pesquisa na área ambiental:

Agora, nos últimos anos para cá, eu tenho visto estas discussões mais em pauta [...] tenho visto interesses assim isolados de um pesquisador, de outro pesquisador propondo projetos que envolvam o contexto do meio em si [...] da grande maioria, poucas pessoas se interessam pelo socioambiental, poucas pessoas, poucos pesquisadores aqui na universidade, não que a universidade nos chame para fazer essa discussão, não percebo isso [...] (CD4)

Uma importante observação foi feita pelo professor P2, que relatou que, além da despreocupação, também existe uma falta de comprometimento dos docentes em inserir tais discussões no contexto universitário, o que, consequentemente, torna-se um fator preponderante para a passividade nas discussões da temática ambiental.

Assim, partindo do princípio de que a intenção da discussão da temática ambiental é promover a compreensão de que a ação do homem causa consequências para o próprio homem, a aproximação dos acadêmicos com as questões ambientais deve buscar conscientizá-los de que a responsabilidade pelas catástrofes, pela degradação do meio ambiente, pela redução dos recursos naturais recai sobre todas as áreas de formação. Para esta aproximação da temática ambiental aos acadêmicos, o caminho é um envolvimento maior da universidade, que pode propiciar mais espaços de discussão da problemática ambiental. Jacobi (2005) afirma que o desafio da ambientalização em âmbito global é a construção de uma comunicação da educação ambiental entre as ciências sociais e exatas. ambiental:

Os depoimentos a seguir evidenciam as dificuldades dos professores na abordagem da temática

[...] às sociais aplicadas, dada a contribuição mais no âmbito da gestão, gestão ambiental, talvez caberia mais uma articulação, até para o próprio setor produtivo entender a demanda deles neste sentido. Mas eu acho que é um problema aí, talvez por ser uma área nova, relativamente nova, talvez também seja um obstáculo, alguma coisa nesse sentido [...]. (P1)

[...] a universidade não é multidisciplinar ainda [...] nas sociais aplicadas eu acredito que tem até uma despreocupação mesmo da universidade e dos próprios docentes [...] acho que ainda está muito fechado para o capital [...] tem uma abertura para isso? Tem, mas é muito pouco e vai depender muito do professor, vai depender das características dos professores porque a universidade não consegue fazer a interdisciplinaridade ainda [...] O problema da universidade não conseguir ser interdisciplinar é tratar muito isoladamente os temas [...] (P2)

A questão ambiental teria que ter um engajamento com outras áreas, como a geografia, pra a gente conseguir avançar mais [...] eu acho que o curso avança nisso porque a maioria dos cursos não tem essa disciplina, e o conteúdo é trabalhado de forma transversal, ou incluso em alguma outra ementa de alguma disciplina mais próxima, ética alguma coisa assim. (P3)

É evidente a preocupação destes professores com a ausência de uma discussão mais abrangente da temática ambiental pela universidade. Nos discursos, observa-se que, para os professores, a discussão não deveria ser contemplada apenas em uma disciplina, mas deveria ser interdisciplinar e transversal. 
Vale destacar que é comum ocorrer na universidade uma distorção de temáticas por influência dos interesses do professor. Ou seja, um professor que ministra uma disciplina com ênfase às discussões ambientais pode, por exemplo, enviesar as discussões para o marketing ambiental e deixar de relacionar os aspectos multidimensionais inseridos na discussão. Neste contexto, é de extrema importância "a construção de metodologias e materiais pedagógicos, com abordagens inovadoras que promovam ações efetivas como alternativas para a construção de sociedades sustentáveis" (GUERRA et al., 2012, p.212).

Não se pode deixar de comentar que, sob o ponto de vista de Pavesi (2012, p. 156), o desafio da efetivação da educação ambiental na universidade é deixar de transmitir aos alunos definições, conhecimentos e busca por soluções, para promover o engajamento na criação de oportunidades e percursos didáticos que incorporem os princípios da sustentabilidade. Somente desta forma os alunos seriam estimulados a avaliarem, constantemente, suas decisões e ações no que tange ao aspecto socioambiental.

Os resultados apresentados evidenciam que, embora existam programas, eventos, leis, e outros instrumentos jurídicos, a educação ambiental ainda não se consolidou na universidade. Para Rivelli (2005), isso ocorre por falta de empenho na divulgação e internalização da problemática ambiental, para, então, promover a consciência dos envolvidos.

De qualquer forma, é indiscutível, segundo Loureiro (2012), que os desafios da educação ambiental precisam ser assumidos e enfrentados, não ignorados. É necessário partir da compreensão de que, na atualidade, a produção do conhecimento é o principal fator que culmina na transformação da sociedade. Por meio do conhecimento, é possível antecipar problemas e soluções que possam emergir na sociedade, que, por sua vez, aspira o desenvolvimento e o progresso.

Sobre a emergência do aprofundamento das discussões na universidade, os entrevistados afirmaram que a universidade, como instituição educativa, tem que buscar a integração da temática, "[...] a universidade está articulada com a sociedade de maneira geral. Então se é um tema que aparece, ela tem que inserir para dentro do currículo, a realidade e a teoria têm que estar dialogando, preparando o profissional para enxergar essas questões [...]" (CD1).

De maneira geral, as entrevistas sugerem que a universidade ainda trata os problemas ambientais de forma independente. Leff (2001) destaca que uma das maiores barreiras para inserir a educação ambiental na universidade é o engessamento da universidade pública por:

políticas econômicas que orientam o apoio à educação, à produção de conhecimentos e à formação profissional, em função de seu valor no mercado. Isto tem criado obstáculos à transformação do conhecimento nas instituições educacionais para incorporar o saber ambiental à formação de recursos humanos que sejam capazes de compreender e resolver os problemas socioambientais do nosso tempo (LEFF, 2001, p. 223).

Neste contexto, Leme et al. (2012) expõem que a internalização dos conceitos amplos e profundos da ambientalização de forma prática é uma tarefa difícil, que exige novas orientações de valores, posturas e atitudes, tanto aos mínimos detalhes do dia a dia quanto com relação às questões planetárias. Os autores ainda argumentam que o debate ambiental na universidade começou a dar os primeiros passos rumo à prática do discurso de desenvolvimento sustentável.

Convém ressaltar que foi somente nos últimos anos que passou a ocorrer uma preocupação maior com as questões ambientais, motivada por legislações ambientais e regulamentações governamentais. Esta concepção é relatada pelo entrevistado P3, ao afirmar que a inserção da temática ambiental na universidade "é um processo meio inicial [...] em função de cobrança do próprio MEC. Mas o fato de cobrar, dessa legislação toda, já desperta que alguma coisa tem que fazer" (P3). Outro entrevistado afirma que "a universidade, no geral, vai desdobrando essa responsabilidade nos cursos e as responsabilidades caem para os professores [...]" (P4).

É dever da universidade colaborar para o desenvolvimento do pensamento crítico, na busca de soluções que possam auxiliar no enfrentamento das causas de degradação ambiental, "caso contrário, será apenas, quando muito, uma universidade que atribui títulos e possibilita empregos melhores ou, ainda, realiza pesquisas financiadas pelos interesses das grandes corporações empresariais" (SORRENTINO et al. 2012, p. 25). 


\section{CONSIDERAÇÕES FINAIS}

A ambientalização universitária se depara com um processo de reformulação do conhecimento, suas relações e amplitude da temática. Contudo, pode-se inferir que, apesar de ser um processo ainda novo, repleto de desafios e anseios dos sujeitos envolvidos, está iniciando as demandas para uma formação socioambiental, preparando os acadêmicos para o exercício profissional, além de estar formando cidadãos ambientalmente comprometidos, cientes das consequências de suas ações e relações com o meio.

Vale observar que a problemática ambiental trata-se de uma discussão que deve ser contextualizada para além dos discursos, em um processo de repensar os efeitos das práticas educativas de educação ambiental e de integrar a problemática ambiental às relações sociais, econômicas, políticas e culturais (FARIAS, 2008).

Nesta direção, a universidade deve cumprir seu papel de direcionar estratégias para fortalecer a capacidade científica, incentivando a pesquisa e o desenvolvimento nos diferentes setores da sociedade, assumindo novas posturas na construção dos projetos político pedagógicos (BARTHOLO JR. e BURSZTYN, 2001). Desta forma, a concretização dos resultados deve estar atrelada a um conjunto de ações que se apoia no ensino, mas deve ir além das barreiras disciplinares.

Sob esta ótica, conclui-se que o sistema universitário deve romper o paradigma fragmentado e isolado de construção do conhecimento, atribuindo à universidade o papel central das discussões sobre os diversos problemas presentes na sociedade, buscando ampliar o escopo das discussões que são construídas e reconstruídas em determinado momento, face às necessidades levantadas pela própria sociedade.

No caso da problemática ambiental, ao mesmo tempo em que são discutidos os diversos processos, causas, consequências, propostas e direcionamentos futuros, a sociedade reivindica mais atenção. Desta forma, a relação sociedade/universidade passa a ser um processo dialético, no qual cabe à universidade a articulação do problema ambiental com o contexto social, cultural, histórico, político, ideológico e econômico (LOUREIRO, 2012).

Neste sentido, Sorrentino et al. (2012, p. 22) argumentam que a educação ambiental na universidade pode cumprir dois papéis: o primeiro refere-se à integralização da própria instituição na questão ambiental, em um processo de ambientalização da instituição que deve permear as atividades de gestão ambiental, ensino, pesquisa e extensão. O segundo papel é a contribuição no processo de educar ambientalmente a sociedade, fomentando práticas e ações educativas. Todavia, a educação ambiental ainda tem um longo caminho no contexto universitário.

\section{REFERÊNCIAS}

BARDIN, I. Análise de conteúdo. Lisboa: Edições Setenta, 1994.

BARTHOLO JR, Roberto S; BURSZTYN, Marcel. Prudência e Utopismo: Ciência e Educação para a Sustentabilidade. In: BURSZTYN, Marcel (org.) 2. ed. São Paulo: Cortez/UNESCO, 2001.

FARIAS, C. R. O. A produção da política curricular nacional para a Educação Superior diante do acontecimento ambiental: problematizações e desafios. 2008. 215 f. Tese (Doutorado em Educação) - Universidade Federal de São Carlos, São Carlos, 2008.

GUERRA, A. F. S. et al. Educação para a sustentabilidade: uma proposta de ambientalização curricular nos cursos de licenciatura e na formação para educação básica. In: LEME, P. C. S.; PAVESI., A.; ALBA, D.; GONZÁLEZ., M. J. D.. (Org.). Visões e experiências ibero-americanas de sustentabilidade nas universidades 1 ed. Madrid: Alambra, 2012, v. 1, p. 211-217.

HAIR JR, J. F. et al. Fundamentos de métodos de pesquisa em administração. Porto Alegre : Bookman, 2005.

JOVCHELOVITCH, S.; BAUER, M. W. Entrevista narrativa. In: BAUER, M. W. ; GASKELL, G. (Org.). 
Pesquisa qualitativa com texto, imagem e som: um manual prático. Petrópolis: RJ. Vozes, 2002. p. 90-113.

LEFF, E. Saber Ambiental: sustentabilidade, racionalidade, complexidade, poder. $5^{a}$ ed., Petrópolis, Rio de Janeiro: Vozes, 2001.

LEME, P. C. S. et al. Visões e experiências ibero-americanas de sustentabilidade nas universidades. 1 ed. Madrid: Alambra, v.1, 2012.

LOUREIRO, C. F. B. Trajetórias e fundamentos da educação ambiental. 4 ed. São Paulo: Cortez, 2012.

PAVESI. A. Uma abordagem prática da ambientalização curricular: a experiência da escola de engenharia de São Carlos (EESC-USP). In: LEME, P. C. S.; PAVESI, A.; ALBA, D.; G., M. J. D.. (Org.). Visões e experiências ibero-americanas de sustentabilidade nas universidades. 1 ed. Madrid: Alambra, 2012, v. 1, p. 151-157.

RICHARDSON, R.J. Pesquisa Social: Métodos e Técnicas. $3^{\text {a }}$ ed. revista e ampliada. São Paulo, Ed. Atlas, 1999.

SACHS, I. Caminhos para o desenvolvimento sustentável. Coleção Ideias Sustentáveis. Rio de Janeiro: Garamond, 2002.

SORRENTINO, M. et al. Universidade, educação ambiental e políticas Públicas. In: LEME, P. C. S.; PAVESI, A.; ALBA, D.; G., M. J. D.. (Org.). Visões e experiências ibero-americanas de sustentabilidade nas universidades. 1 ed. Madrid: Alambra, 2012, v. 1, p. 19-27.

TONSO, S. A ambientalização da universidade e a extensão Universitária. In: LEME, P. C. S.; PAVESI., A.; ALBA, D.; GONZÁLEZ., M. J. D.. (Org.). Visões e experiências ibero-americanas de sustentabilidade nas universidades. 1 ed. Madrid: Alambra, 2012, v. 1, p. 65-70.

YIN, R. K. Estudo de caso: planejamento e métodos. 3 ed. Porto Alegre: Bookman, 2005. 